\title{
A comparison of McGrath MAC, Pentax AWS, and Macintosh direct laryngoscopes for nasotracheal intubation: a randomized controlled trial
}

This article was published in the following Dove Press journal:

Therapeutics and Clinical Risk Management

\author{
Yun Jeong Chae* \\ Dae Hee Kim* \\ Eun Jeong Park \\ Juyeon $\mathrm{Oh}$ \\ In Kyong Yi
}

Department of Anesthesiology and Pain Medicine, Ajou University School of Medicine, Suwon 16499, South Korea

*These authors contributed equally to this work
Correspondence: In Kyong Yi

Department of Anaesthesiology and Pain Medicine, Ajou University School of

Medicine, 164 World Cup-ro, Yeongtong-gu,

Suwon 16499, South Korea,

Tel +822197522

Fax +82 2195579

Email lyrin0I@gmail.com
Purpose: Videolaryngoscopy in nasotracheal intubation has been reported to be better than direct laryngoscopy. The most suitable type of videolaryngoscope remains unknown. This study aimed to compare two videolaryngoscopes (McGrath MAC and Pentax AWS) with a Macintosh laryngoscope during nasotracheal intubation.

Methods: Overall, 123 patients older than 18 with normal airways who needed nasotracheal intubation were randomly allocated into three groups: Macintosh $(n=41)$, McGrath $(n=41)$, and Pentax $(n=41)$. Intubation time was the primary outcome and subdivided into three steps: nose to oropharynx, oropharynx to laryngeal inlet, and laryngeal inlet to trachea. Time required, ease of each step, glottic view grade, modified nasal intubation-difficulty score, and subjective difficulty were evaluated.

Results: Intubation time among the three groups was not significantly different (Macintosh 34.6 \pm 8.1 seconds, McGrath 35.2 \pm 7.9 seconds, Pentax 36.2 \pm 9.7 seconds; $p=0.727$ ). While the glottal view was better with videolaryngoscopes (I/IIa/IIb/III 36.6\%/36.6\%/19.5\%/7.3\% vs $82.9 \% / 9.8 \%$ / $7.3 \% / 0 \%$, vs $63.4 \% / 29.3 \% / 4.9 \% / 2.4 \%, p=0.000$ ), modified nasal intubation-difficulty score and subjective difficulty and ease of each step were not significantly different. However, the Pentax took longest for the second step ( $11.8 \pm 6.3$ vs $10.3 \pm 3.5$ vs $15.1 \pm 7.6$ seconds, $p=0.001)$ but was shortest for the third step ( $2.9 \pm 2.6$ vs $4.4 \pm 5.6$ vs $1.7 \pm 0.7$ seconds, $p=0.001)$.

Conclusion: The McGrath MAC and Pentax AWS showed no benefits in intubation time or difficulty, despite better glottal views, compared to the Macintosh laryngoscope in nasotracheal intubation. Additionally, videolaryngoscopes had variable performance at different steps of nasotracheal intubation.

Keywords: laryngoscopes, laryngoscopy, intubation, trachea, nose

\section{Introduction}

Nasotracheal intubation is often required during oral or maxillofacial operations. Similarly to orotracheal intubation, nasotracheal intubation becomes difficult with poor laryngoscopic views. Furthermore, even under excellent laryngeal views, the navigation of tube to trachea is often difficult in nasotracheal intubation compared to orotracheal intubation. Nasotracheal intubation can thus lead to extension of intubation time, which can be associated with major problems, including hypoxia and hypertension. ${ }^{1,2}$ Numerous reports have suggested that utilization of videolaryngoscopy during nasotracheal intubation results in better clinical outcomes than direct laryngoscopy. ${ }^{3-8}$

Various videolaryngoscopes, such as the Airtraq, McGrath, C-MAC, GlideScope, and Pentax AWS, are available. Videolaryngoscopes can be categorized according to 
the blade shape and presence of channel guides. With a steep angled blade without a channel guide, the GlideScope has shorter intubation times and an easier procedure compared to the Pentax AWS or Macintosh direct laryngoscopy. ${ }^{9}$ The McGrath MAC has shown shorter intubation time over Macintosh laryngoscopy, while Pentax AWS has not. ${ }^{10}$ There have been few studies ${ }^{9,11}$ comparing different types of videolaryngoscope during nasotracheal intubation, and the most suitable type of videolaryngoscope for nasotracheal intubation remains unknown. The current study thus compared two types of videolaryngoscope - the McGrath MAC and Pentax AWS - with a Macintosh direct laryngoscope during nasotracheal intubation. We measured intubation time and ease of operation, both overall and for subdivided steps.

\section{Methods}

All study protocols were approved by the Ajou Institutional Review Board (AJIRB-MED-OBS-170327, November 6, 2017) and the current trial was registered with ClinicalTrials.gov (NCT03337555, November 9, 2017). Written informed consent was obtained from the patients. Patients aged $>18$ years with an American Society of Anesthesiologists class 1 or 2 who were scheduled to undergo elective dental surgery under general anesthesia with nasotracheal intubation were enrolled. Participants who had anticipated difficult airway that included oropharyngeal congenital anomaly and modified Mallampati score IV were excluded. Participants who had bleeding tendencies in their preoperative evaluation were also excluded. Participants were randomized and allocated into three groups depending on the device used for intubation: Macintosh group, McGrath group, and Pentax group. An independent colleague not involved with this research conducted the random group assignment using randomization software. Immediately before anesthesia was administered, a sealed opaque envelope containing a number indicating the selected laryngoscope was provided to the anesthesiologist and opened in the operating room. The videolaryngoscopes used for this study were the McGrath MAC (Medtronic, Minneapolis, MN, USA) and Pentax AWS (Hoya, Tokyo, Japan), and the tube used was a Polar preformed tracheal tube (Portex; Smith Medical, Minneapolis, MN, USA).

Participants entered the operation theater without premedication, a routine monitor was placed, and baseline hemodynamic data recorded. Before induction, the patient was asked which nostril was easier to breathe through. If patients had no preference, we usually chose the right nostril. For induction, fentanyl $1 \mu \mathrm{g} / \mathrm{kg}$ and thiopental 4 $5 \mathrm{mg} / \mathrm{kg}$ were given. After patients had lost consciousness, rocuronium $0.6 \mathrm{mg} / \mathrm{kg}$ was given and manual ventilation done with $100 \%$ oxygen and $4 \%-6 \%$ sevoflurane. After 2 minutes, nasotracheal intubation was conducted using the assigned device by an expert anesthesiologist who was used to all three devices. In the Pentax group, the blade tip was inserted vallecularly or posteriorly to the epiglottis according to the position of the tip shown on the video screen at insertion of the blade.

The primary performance parameter was intubation time, measured by a separate observer with a video recorder and timer. Intubation time was defined as the time from passage of the nasotracheal tube past the nostril to appearance of end-tidal $\mathrm{CO}_{2}$ on the monitor. Secondary parameters were success rate, and "failure" defined intubation time $>120$ seconds, esophageal intubation regardless of time required, or oxygen-saturation decrease $<95 \%$ during the procedure. The degree of epistaxis was also measured (1, no epistaxis; 4 , severe; blood to impend intubation). The intubator provided CormackLehane laryngeal view grade, modified nasal intubation-difficulty score (Table 1$),{ }^{12}$ and subjective difficulty score $(0$, extremely easy; 10 , extremely difficult). The whole process was recorded and divided into three steps according to steps of tube passage. The observer recorded the time required for each step using video recording, while the easiness of each step was evaluated by the intubator. The first step was defined as tube passage from nose to oropharynx. The ease of the first step was graded as 1, pass easily 2 need rotate to pass, and 3 give up and choose contralateral nostril. The second step was defined as tube passage from oropharynx to laryngeal inlet, specifically starting from the moment the laryngoscope passed the incisors to the moment of arrival of tube at the laryngeal inlet. The intubator was instructed to notify by voice when the tube arrived at the laryngeal inlet. The observer evaluated the duration, and the intubator evaluated ease as described by Patil et al (Table 2). ${ }^{5}$ The third step was defined as tube passage from laryngeal inlet to trachea, where the nasotracheal tube passes the vocal cord. The observer e valuated the duration and the intubator graded ease.

\section{Sample-size calculation and statistical analysis}

A prior study on nasotracheal intubation reported an SD of 15.5 seconds. ${ }^{4}$ Clinical significance was considered as $>10$ second difference between devices, the minimum number of patients for each group was 37 , and considering the $10 \%$ 
Table I Modified nasal intubation-difficulty scale (MNIDS). ${ }^{12}$

\begin{tabular}{|l|l|}
\hline Parameter & Score \\
\hline NI: Intubation attempts & Each additional intubation attempts after the first one adds I point \\
\hline N2: Operators to attempt intubation & Each additional operator required to attempt intubation adds I point \\
\hline N3: Alternative intubation techniques or change head position & Each alternative technique or change of head position adds I point \\
\hline N4: glottis exposure & $\begin{array}{l}0=\text { good visualization of vocal cords with little manipulation } \\
\text { I = tools manipulated in all directions to identify the vocal cords } \\
2=\text { tools extensively manipulated in all directions to identify the vocal cords }\end{array}$ \\
\hline N5: Lifting force required to expose the vocal cords & $\begin{array}{l}0=\text { lifting without assistance } \\
I=\text { lifting required by assistant to improve view of the vocal cords }\end{array}$ \\
\hline N6: Optimize glottis exposure with BURP & $\begin{array}{l}0=\text { none } \\
\text { I = BURP applied }\end{array}$ \\
\hline N7: Techniques to aid intubation & $\begin{array}{l}0=\text { none } \\
I=\text { cuff inflation or use of Magill forceps }\end{array}$ \\
\hline
\end{tabular}

Notes: Reproduced from: Lee MC, Tseng KY, Shen YC, et al.Nasotracheal intubation in patients with limited mouth opening: a comparison between fibreoptic intubation and the Trachway(R). Anaesthesia. 2016;7I(I):31-38, with permission from John Wiley and Sons. ${ }^{12}$

Abbreviation: BURP, backward-upward-rightward pressure.

Table 2 Ease of second step using sequence of additional maneuvers. $^{5}$

\begin{tabular}{|l|l|}
\hline Grade & Maneuvers \\
\hline M0 & Intubation without maneuvers \\
\hline MI & $\begin{array}{l}\text { Use of external manipulations, such as tube rotation, head } \\
\text { flexion, BURP maneuver }\end{array}$ \\
\hline M2 & Use of ETT cuff inflation alone \\
\hline M3 & Use of ETT cuff inflation with external manipulation (MI + M2) \\
\hline M4 & Use of Magill forceps alone \\
\hline M5 & Use of Magill forceps with external manipulation (MI + M4) \\
\hline
\end{tabular}

Note: Reproduced from: Patil VV, Subramanya BH, Kiranchand N, Bhaskar SB, Dammur S. Does C-MAC ((R)) video laryngoscope improve the nasotracheal intubating conditions compared to macintosh direct laryngoscope in paediatric patients posted for tonsillectomy surgeries? 2016;60(I0):732-736. http://www.ijaweb.org/. ${ }^{5}$ Abbreviations: BURP, backward-upward-rightward pressure; ETT, endotracheal tube.

dropout rate, we planned to enroll 41 patients for each group $(\alpha=0.05, \beta=0.2)$. All statistical analyses were conducted using SPSS 23.0 (IBM, Armonk, NY, USA). Continuous parametric data were compared using two-tailed $t$-tests, while nonparametric data were compared using Mann--Whitney $U$ tests. For categorical data, we used either $\chi^{2}$ tests or Fisher's exact tests (significance at $p<0.05$ ).

\section{Results}

A total of 123 patients, 41 in each group, completed the study (Figure 1). Demographic data of patient age, weight, height, American Society of Anesthesiologists class, and tube size were not significantly different among the groups (Table 3). In all three groups, right-nostril intubation was dominant. Total intubation time was not significantly different (Macintosh 34.6 \pm 8.1 seconds, McGrath 35.2 \pm 7.9 seconds, Pentax 36.2 \pm 9.7 seconds; $p=0.727$ ). There were no failures in any of the groups. McGrath and Pentax had more Cormack-Lehane laryngeal view grade I than Macintosh (Macintosh 15 (36.6\%), McGrath 34 (82.9\%), Pentax $26(63.4 \%) ; p=0)$. Modified nasal intubation-difficulty score, subjective difficulty score, and degree of epistaxis were not different among the groups (Table 4).

As mentioned previously, intubation time was divided into three steps regarding passage of the endotracheal tube. Neither intubation time nor ease was different in the groups in the first step (nose to oropharynx). As for time required in the second step, oropharynx to laryngeal inlet, the Pentax took longer than the McGrath (Macintosh 11.8 \pm 6.3 seconds, McGrath 10.3 \pm 3.5 seconds, Pentax 15.1 \pm 7.6 seconds, $p=0.001$ ). But there was no difference among groups in terms of easiness during the second step. As for the time required in the third step, laryngeal inlet to trachea, the Pentax required the least time (Macintosh 2.9 \pm 2.6 seconds, McGrath 4.4 \pm 5.6 seconds, Pentax $1.7 \pm 0.7$ seconds; $p=0.001)$. Ease showed no difference in the third step among groups (Table 5). The incidence of using additional maneuvers was not different among groups, including backward-upward-rightward pressure, Magill forceps, head flexion, cuff inflation, and tube rotation (Table 6). 


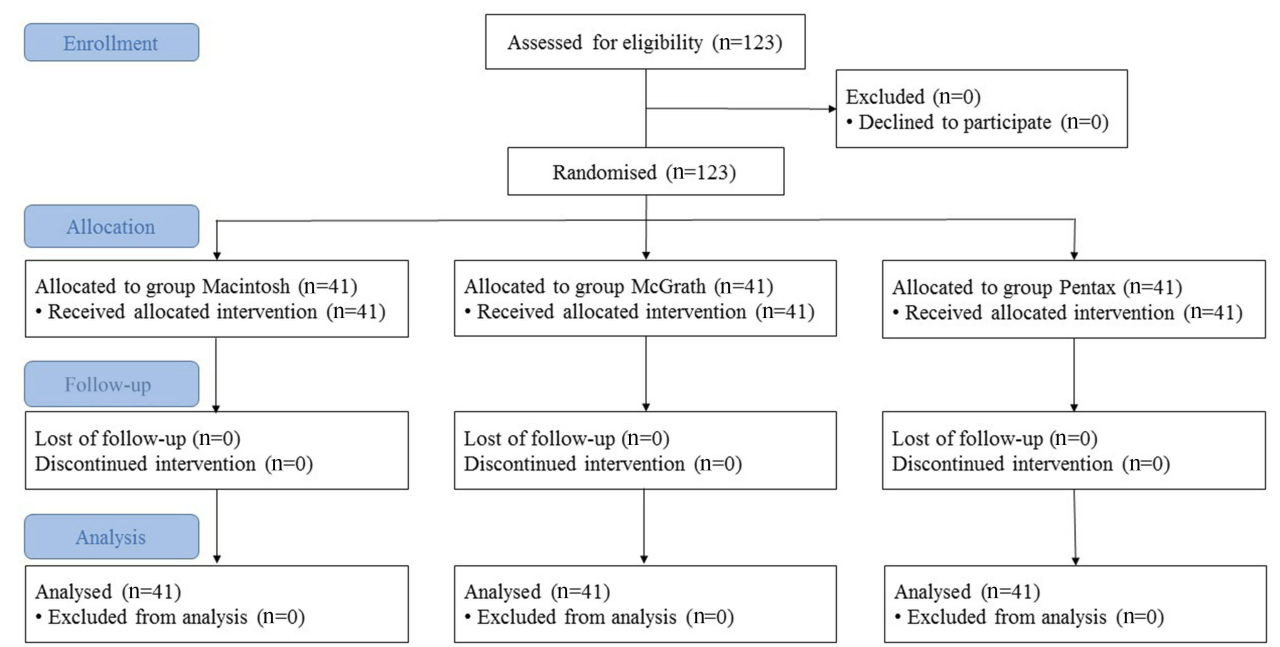

Figure I CONSORT flow diagram.

Table 3 Patient characteristics

\begin{tabular}{|l|l|l|l|}
\hline Parameters & Macintosh $(\mathbf{n = 4})$ & McGrath (n=4I) & Pentax (n=4I) \\
\hline Male sex, $\mathbf{n}(\%)$ & $23(56.1)$ & $30(73.2)$ & $22(53.7)$ \\
\hline Age, years & $34.6 \pm 13.9$ & $35.9 \pm 14.0$ & $38.9 \pm 15.3$ \\
\hline Weight, kg & $63.2 \pm 13.0$ & $67.3 \pm 14.6$ & $64.7 \pm 12.5$ \\
\hline Height, cm & $167.5 \pm 8.8$ & $168.9 \pm 9.2$ & $167.6 \pm 10.2$ \\
\hline $\begin{array}{l}\text { ASA, } \mathbf{n}(\%) \\
\text { I/II }\end{array}$ & $37(90.2) / 4(9.8)$ & $37(90.2) / 4(9.8)$ & $35(85.4) / 6(14.6)$ \\
\hline $\begin{array}{c}\text { Tube size, ID (mm) } \\
6.0 / 6.5\end{array}$ & $18(43.9) / 23(56.1)$ & $12(29.3) / 29(70.7)$ & $19(46.3) / 22(53.7)$ \\
\hline $\begin{array}{c}\text { Nostril, } \mathbf{n}(\%) \\
\text { Left/right }\end{array}$ & $3(7.3) / 38(92.7)$ & $5(12.2) / 36(87.8)$ & $2(4.9) / 39(95.1)$ \\
\hline
\end{tabular}

Note: Values are means \pm SD or $n(\%)$.

Abbreviations: ASA, American Society of Anesthesiologists (physical status); ID, internal diameter.

\section{Discussion}

Our study showed that the two types of videolaryngoscope had no benefit on intubation time or difficulty compared to the Macintosh direct laryngoscope during nasotracheal intubation, despite a better laryngeal view. The Pentax AWS, however, showed differences in intubation time compared with the other devices, in that it took longer for the nasotracheal tube to pass from the oropharynx to the laryngeal inlet, while it took less time for the tube to pass the laryngeal inlet compared to other devices.

Previous studies regarding videolaryngoscopes for nasotracheal intubation mostly report shorter total intubation time for videolaryngosopy compared to Macintosh direct laryngoscopy. ${ }^{3,4,7-9}$ Previously published nasotracheal intubation times for the Pentax AWS (36.4-38.4 seconds) and McGrath (34.4-36.5 seconds) were similar to our study results, while the Macintosh $(36.5-44.9 \mathrm{sec})$ was shorter in our study (34.6 seconds). ${ }^{4,9,10}$ The shorter intubation time of the Macintosh possibly resulted in overall similar intubation times for all devices in our study. Unlike orotracheal intubation, where exposure of the glottis takes time, the most time-consuming step during nasotracheal intubation is navigating the tube. The overall intubation time during nasotracheal intubation increases when additional maneuvers are performed. ${ }^{10,13-15}$ A number of studies report that the use of videolaryngoscopes reduces the requirement of such maneuvers, and thus may have resulted in an overall shorter intubation time compared to direct layrngoscopes. Tseung 
Table 4 Intubation profiles

\begin{tabular}{|c|c|c|c|c|}
\hline Parameters & Macintosh $(n=4 I)$ & McGrath $(n=4 I)$ & Pentax $(n=4 I)$ & $p$-value \\
\hline Cormack-Lehane grade, n (\%) & & & & 0 \\
\hline I & $15(36.6)$ & $34(82.9)$ & $26(63.4)$ & \\
\hline lla & $15(36.6)$ & $4(9.8)$ & $12(29.3)$ & \\
\hline $\mathrm{llb}$ & $8(19.5)$ & $3(7.3)$ & $2(4.9)$ & \\
\hline III & $3(7.3)$ & $0(0)$ & I (2.4) & \\
\hline Success rate, $\mathbf{n}(\%)$ & $4 I(100)$ & $4 I(100)$ & $4 I(100)$ & I \\
\hline Difficulty & $0.5(0-1)$ & $0(0-1)$ & $0(0-1)$ & 0.741 \\
\hline \multicolumn{5}{|l|}{ MNIDS } \\
\hline Total & $0(0-0)$ & $0(0-0)$ & $0(0-0)$ & 0.283 \\
\hline NI 0/I/2, n (\%) & $39 / 2 / 0(95.1 / 4.9 / 0)$ & $39 / 2 / 0(95.1 / 4.9 / 0)$ & $38 / 2 / 1(92.7 / 4.9 / 2.4)$ & 1 \\
\hline N2 0/I, n (\%) & $41 / 0(100 / 0)$ & $4 \mathrm{I} / 0(100 / 0)$ & $4 \mathrm{I} / 0(100 / 0)$ & - \\
\hline N3 0/I, n (\%) & $40 / 1(97.6 / 2.4)$ & $41 / 0(100 / 0)$ & $40 / 1(97.6 / 2.4)$ & 1 \\
\hline N4 0/I/2, n (\%) & $36 / 5 / 0(87.8 / / 2.2 / 0)$ & $39 / 2 / 0(95.1 / 4.9 / 0)$ & $37 / 4 / 0(90.2 / 9.8 / 0)$ & 0.621 \\
\hline N5 0/I, n (\%) & $36 / 5(87.8 / 12.2)$ & $39 / 2(95.1 / 4.9)$ & $37 / 4(90.2 / 9.8)$ & 0.621 \\
\hline N6 0/I, n (\%) & $33 / 8(80.5 / 19.5)$ & $38 / 3(92.7 / 7.3)$ & $39 / 2(95.1 / 4.9)$ & 0.140 \\
\hline N7 0/I, n (\%) & $38 / 3(92.7 / 7.3)$ & $40 / 1(97.6 / 2.4)$ & $4 \mathrm{I} / 0(100 / 0)$ & 0.322 \\
\hline \multicolumn{5}{|l|}{ Epistaxis } \\
\hline I/2/3/4, n (\%) & $29 / 12 / 0 / 0(70.7 / 29.3 / 0 / 0)$ & $30 / 1 \mathrm{l} / 0 / 0(73.2 / 26.8 / 0 / 0)$ & $30 / 1 \mathrm{I} / 0 / 0(73.2 / 26.8 / 0 / 0)$ & 1 \\
\hline
\end{tabular}

Notes: Values are means $\pm S D$, median $(I Q R)$, or $n(\%)$. Difficulty and subjective difficulty represented by numeric rating scale $(I=$ extremely easy, $10=$ extremely difficult). Abbreviation: MNIDS, modified nasotracheal intubation-difficulty score.

Table $\mathbf{5}$ Intubation profile according by step

\begin{tabular}{|c|c|c|c|c|}
\hline Parameters & Macintosh $(n=4 I)$ & McGrath $(n=4 I)$ & Pentax $(n=4 I)$ & $p$-value \\
\hline Total intubation time, seconds & $34.6 \pm 8.1$ & $35.2 \pm 7.9$ & $36.2 \pm 9.7$ & 0.727 \\
\hline \multicolumn{5}{|l|}{ First step } \\
\hline Time, seconds & $6.5 \pm 3.9$ & $6.8 \pm 3.4$ & $5.3 \pm 4.1$ & 0.185 \\
\hline \multicolumn{5}{|l|}{ Easiness } \\
\hline $\mathrm{I} / 2 / 3, \mathrm{n}(\%)$ & $27 / 10 / 4(65.9 / 24.4 / 9.8)$ & $23 / 12 / 6(56.1 / 29.3 / 14.6)$ & $34 / 3 / 3(85.0 / 7.5 / 7.5)$ & 0.059 \\
\hline \multicolumn{5}{|l|}{ Second step } \\
\hline Time, seconds & $11.8 \pm 6.3$ & $10.3 \pm 3.5$ & $|5| \pm 7.6$. & 0.001 \\
\hline Ease, n (\%) & & & & 0.099 \\
\hline Mo & $30(73.2)$ & $36(87.8)$ & $29(70.7)$ & \\
\hline MI & $8(19.5)$ & $4(9.8)$ & $12(29.3)$ & \\
\hline M2 & $2(4.9$ & $\mathrm{I}(2.4)$ & 0 & \\
\hline M3 & 0 & 0 & 0 & \\
\hline M4 & 0 & 0 & 0 & \\
\hline M5 & I (2.4) & 0 & 0 & \\
\hline \multicolumn{5}{|l|}{ Third step } \\
\hline Time, seconds & $2.9 \pm 2.6$ & $4.4 \pm 5.6$ & $1.7 \pm 0.7$ & 0.001 \\
\hline \multicolumn{5}{|l|}{ Ease } \\
\hline I/2/3, n (\%) & $31 / 10 / 0(75.6 / 24.4 / 0)$ & $28 / 13 / 0(68.3 / 31.7 / 0)$ & $37 / 4 / 0(90.2 / 9.8 / 0)$ & 0.058 \\
\hline
\end{tabular}

Notes: Values are means $\pm S D$, median (IQR), or $n$ (\%). First step, nose to oropharynx; second step, oropharynx to laryngeal inlet; third step, laryngeal inlet to trachea. The ease of the second step was evaluated according to Table 2. 
Table 6 Maneuvers

\begin{tabular}{|l|l|l|l|l|}
\hline Maneuver & Macintosh (n=4I) & McGrath $(\mathbf{n}=4 \mathbf{I})$ & Pentax $(\mathbf{n}=4 \mathbf{I})$ & $\mathbf{p}$-value \\
\hline BURP & $8(19.5)$ & $4(9.8)$ & $3(7.3)$ & 0.303 \\
Magill forceps & $\mathrm{I}(2.4)$ & 0 & 0 & $0.22 \mathrm{I}$ \\
Head flexion & 0 & 0 & $I(2.4)$ & $0.22 \mathrm{I}$ \\
Cuff inflation & $2(4.9)$ & $\mathrm{I}(0.8)$ & 0 & 0.064 \\
Tube rotation & $\mathrm{I}(43.9)$ & $19(46.3)$ & $15(36.6)$ & 0.720 \\
\hline
\end{tabular}

Note: Values are $\mathrm{n}(\%)$.

Abbreviation: BURP, backward-upward-rightward pressure.

et al reported that use of the GlideScope or Pentax AWS resulted in diminished use of backward-upward-rightward pressure. ${ }^{9}$ St Mont et al also reported less use of maneuvers during Airtraq use, ${ }^{3}$ and Kwak et al reported that use of the McGrath videolaryngoscope resulted in less use of Magill forceps than Macintosh direct laryngoscopy. ${ }^{4}$ The results of our study did not show differences in maneuver use among the three groups, and this may have influenced the similar intubation times.

The use of the Portex north polar tube in this study may have contributed to the reduction in maneuver use in the Macintosh group, as it is designed to allow easier guidance of tracheal tubes to the glottis. Ozkan et $\mathrm{al}^{16}$ reported that north polar tube was associated with fewer maneuvers than the spiral tube during Macintosh laryngoscopy. It is presumed that the performance of the Macintosh laryngoscope may be influenced by composition, coating, and design of the tube, which may have affected the results of the comparative study. ${ }^{16-18} \mathrm{~A}$ study comparing Airtaq and Macintosh laryngoscopy reported no difference in intubation time for easy intubation cases, while Airtaq use resulted in shorter intubation compared to Macintosh laryngoscopy for difficult intubation cases. ${ }^{3}$ Our study included patients with normal airways and relatively easy intubation cases, and thus may have resulted in less difference among groups. Furthermore, intubation conducted by an anesthesiologist familiar with the Macintosh laryngoscope in our study may also also affected the final outcome.

There was no significant difference in easiness of procedure among the three groups in our study, which differs from previous reports. Studies have reported that most videolaryngoscopes were easier to use than Macintosh direct laryngoscopy during nasotracheal intubation., ${ }^{9,15}$ Such factors as enrollment of normal-airway patients only, no significant difference in additional maneuver use among groups, and intubation performed by experts may have affected the similar outcome for all three groups in terms of objective easiness. A study that enrolled ankylosing spondylitis patients reported easier intubation with GlideScope use than Macintosh use. ${ }^{20}$ Enrollment of difficult-airway patients may have accentuated the benefits of videolaryngoscopes.

An interesting finding in our study was that during Pentax AWS use, the second step of intubation (oropharynx to laryngeal inlet) took significantly longer, while the third step of intubation (laryngeal inlet to trachea) was shorter compared to other devices. Reasons for the prolonged second step may have been several in number. The Pentax AWS has a bulky Intlock design containing the tube-guiding channel, which often delays the scope-insertion process. ${ }^{21-23}$ Nowadays, a thinner blade is available, but we used the original blade in this study. The second step here starts from the moment the laryngoscope passed the incisors, which meant that the laryngoscope-insertion time was included in the second step. In addition, the narrow view provided by the Pentax AWS may have made navigation in the oropharynx difficult, as it may take longer for the tube to appear in sight. ${ }^{11}$ on the other hand, the duration of the third step (laryngeal inlet to vocal cord) was shorter in the Pentax AWS group than the other two groups. Of note, the endotracheal tube being impeded in the laryngeal inlet $>10$ second occurred in five and two cases in the Macintosh and McGrath groups, respectively. These two devices require the laryngoscope to be lifted anteriorly during intubation, causing the larynx to displace anteriorly, which in turn may cause posterior vocal cord tissue to impede the tube. ${ }^{24}$ Such change in the airway axis requires additional maneuvers, such as lifting the head and cuff inflation to keep the tube anterior. ${ }^{25}$ The Pentax AWS has a rigid scope and requires minimal lifting force. Such design may have minimized airway distortion. ${ }^{26}$ Considering the blind nasotracheal intubation-success rate without any lifting force is about $70 \%$, the diminished lifting force may be beneficial in terms of alignment during nasotracheal intubation. ${ }^{27}$ Taking into account such design features of the Pentax AWS, videolaryngoscope designs with a thinner blade, wider view, and rigid tube requiring less lifting force may be beneficial for nasotracheal intubation 
One of the limitations in our study was that the intubator was not blinded from the devices. We used the Cormack-Lehane grading system for evaluation of the glottis view. This system, however, is not currently validated for evaluating risk of difficult or failed intubation during videolaryngoscopy. Unfortunately, no other adequate evaluation system exists for this purpose. ${ }^{28}$ This study also enrolled normal-airway patients only, and thus our results cannot be extrapolated to all patients. Furthermore, additional studies including anticipated difficult-airway patients are required to establish the role of videolaryngoscopes in nasotracheal intubation.

In conclusion, the McGrath MAC and Pentax AWS showed no benefits in intubation time compared to the Macintosh laryngoscope in nasotracheal intubation. Intubation difficulty also showed no difference among groups, but video laryngoscopes provided better glottis views. The two types of videolaryngoscope showed different performance at each step of nasotracheal intubation.

\section{Data sharing statement}

The authors can provide the raw data upon reasonable request. The data will be available for 1 year after publication.

\section{Disclosure}

The authors declare no conflicts of interest in this work.

\section{References}

1. Lascarrou JB, Boisrame-Helms J, Bailly A, et al. Video laryngoscopy vs direct laryngoscopy on successful first-pass orotracheal intubation among ICU Patients: a randomized clinical trial. Jama. 2017;317 (5):483-493. doi:10.1001/jama.2016.20603

2. Smith JE, Grewal MS. Cardiovascular effects of nasotracheal intubation. Anaesthesia. 1991;46(8):683-686. doi:10.1111/j.1365-2044.1991. tb09724.x

3. St Mont G, Biesler I, Pfortner R, Mohr C, Groeben H. Easy and difficult nasal intubation-a randomised comparison of macintosh vs Airtraq(R) laryngoscopes. Anaesthesia. 2012;67(2):132-138. doi:10.1111/j.13652044.2011.06943.x

4. Kwak HJ, Lee SY, Lee SY, Cho SH, Kim HS, Kim JY. McGrath video laryngoscopy facilitates routine nasotracheal intubation in patients undergoing oral and maxillofacial surgery: a comparison with macintosh laryngoscopy. J Oral Maxillofac Surg. 2016;74(2):256-261. doi:10.1016/j.joms.2015.07.021

5. Patil VV, Subramanya BH, Kiranchand N, Bhaskar SB, Dammur S. Does C-MAC $((\mathrm{R}))$ video laryngoscope improve the nasotracheal intubating conditions compared to macintosh direct laryngoscope in paediatric patients posted for tonsillectomy surgeries? Indian J Anaesth. 2016;60(10):732-736. doi:10.4103/0019-5049.191676

6. Heuer JF, Heitmann S, Crozier TA, Bleckmann A, Quintel M, Russo SG. A comparison between the GlideScope(R) classic and GlideScope (R) direct video laryngoscopes and direct laryngoscopy for nasotracheal intubation. J Clin Anesth. 2016;33:330-336. doi:10.1016/j. jclinane.2016.04.022
7. Hirabayashi Y, Hoshijima H, Kuratani N, Masaki E. Efficacy of videolaryngoscopes for nasotracheal intubation: a meta-analysis of randomized controlled trials. Masui. 2013;62(11):1375-1379.

8. Hazarika H, Saxena A, Meshram P, Kumar Bhargava A. A randomized controlled trial comparing $\mathrm{C}$ Mac D blade and macintosh laryngoscope for nasotracheal intubation in patients undergoing surgeries for head and neck cancer. Saudi J Anaesth. 2018;12(1):35-41. doi:10.4103/sja.SJA_239_17

9. Tseng KY, Lu IC, Shen YC, Lin CH, Chen PN, Cheng KI. A comparison of the video laryngoscopes with macintosh laryngoscope for nasotracheal intubation. Asian J Anesthesiol. 2017;55(1):17-21. doi:10.1016/j.aja.2017.05.006

10. Sato Boku A, Sobue K, Kako E, et al. The usefulness of the McGrath MAC laryngoscope in comparison with airwayscope and macintosh laryngoscope during routine nasotracheal intubation: a randomaized controlled trial. BMC Anesthesiol. 2017;17(1):160. doi:10.1186/ s12871-017-0451-y

11. Yoo JY, Chae YJ, Lee YB, Kim S, Lee J, Kim DH. A comparison of the macintosh laryngoscope, McGrath video laryngoscope, and pentax airway scope in paediatric nasotracheal intubation. Sci Rep. 2018;8(1):17365. doi:10.1038/s41598-018-35857-8

12. Lee MC, Tseng KY, Shen YC, et al. Nasotracheal intubation in patients with limited mouth opening: a comparison between fibreoptic intubation and the Trachway(R). Anaesthesia. 2016;71(1):31-38. doi:10.1111/anae.13232

13. Hall CE, Shutt LE. Nasotracheal intubation for head and neck surgery. Anaesthesia. 2003;58(3):249-256. doi:10.1046/j.1365-2044. 2003.03034.x

14. Cossham PS. Nasotracheal tube placement over a bougie. Anaesthesia. 1997;52(2):184-185.

15. Jones PM, Armstrong KP, Armstrong PM, et al. A comparison of glidescope videolaryngoscopy to direct laryngoscopy for nasotracheal intubation. Anesth Analg. 2008;107(1):144-148. doi:10.1213/ ane.0b013e31816d15c9

16. Ozkan ASM, Akbas S, Toy E, Durmus M. North polar tube reduces the risk of epistaxis during nasotracheal intubation: a prospective, randomized clinical trial. Curr Ther Res Clin Exp. 2019;90:21-26. doi:10.1016/j.curtheres.2018.09.002

17. Moustafa MA, Ossman YM. Nasotracheal intubation with parker flex-tip versus preformed nasal endotracheal tubes for children undergoing adenotonsillectomy. Middle East J Anaesthesiol. 2016;23 (6):625-629.

18. Sugiyama K, Manabe Y, Kohjitani A. The parker flex-Tip(R) tube prevents subglottic impingement on the tracheal wall during nasotracheal intubation. Anesth Analg. 2012;115(1):212-213. doi:10.1213/ ANE.0b013e3182580f8e

19. Puchner W, Drabauer L, Kern K, et al. Indirect versus direct laryngoscopy for routine nasotracheal intubation. J Clin Anesth. 2011;23 (4):280-285. doi:10.1016/j.jclinane.2010.10.003

20. Lili X, Zhiyong H, Jianjun S. A comparison of the GlideScope with the macintosh laryngoscope for nasotracheal intubation in patients with ankylosing spondylitis. J Neurosurg Anesthesiol. 2014;26 (1):27-31. doi:10.1097/ANA.0b013e31829a0491

21. Abdallah R, Galway U, You J, Kurz A, Sessler DI, Doyle DJ. A randomized comparison between the pentax AWS video laryngoscope and the macintosh laryngoscope in morbidly obese patients. Anesth Analg. 2011;113(5):1082-1087. doi:10.1213/ANE.0b013e31822cf47d

22. Ogino Y, Uchiyama K, Hasumi M, Ninomiya H, Tomioka A, Saito S. A pitfall of AirWay scope-an experience of distinctive airway edema after palatal laceration caused by AirWay scope. Masui. 2008;57 (10): $1245-1248$.

23. Kleine-Brueggeney M, Greif R, Schoettker P, Savoldelli GL, Nabecker S, Theiler LG. Evaluation of six videolaryngoscopes in 720 patients with a simulated difficult airway: a multicentre randomized controlled trial. $\mathrm{Br} J$ Anaesth. 2016;116(5):670-679. doi:10.1093/bja/aew058 
24. Hirabayashi Y, Seo N. Nasotracheal intubation using the airtraq versus macintosh laryngoscope: a manikin study. Anesth Prog. 2008;55(3):78-81. doi:10.2344/0003-3006-55.3.78

25. Gorback MS. Inflation of the endotracheal tube cuff as an aid to blind nasal endotracheal intubation. Anesth Analg. 1987;66(9):916-917.

26. Suzuki A, Toyama Y, Katsumi N, et al. The pentax-AWS((R)) rigid indirect video laryngoscope: clinical assessment of performance in 320 cases. Anaesthesia. 2008;63(6):641-647. doi:10.1111/j.13652044.2008.05452.x
27. Dong Y, Li G, Wu W, Su R, Shao Y. Lightwand-guided nasotracheal intubation in oromaxillofacial surgery patients with anticipated difficult airways: a comparison with blind nasal intubation. Int J Oral Maxillofac Surg. 2013;42(9):1049-1053. doi:10.1016/j. ijom.2013.01.027

28. O'Loughlin EJ, Swann AD, English JD, Ramadas R. Accuracy, intra- and inter-rater reliability of three scoring systems for the glottic view at videolaryngoscopy. Anaesthesia. 2017;72(7):835-839. doi:10.1111/ anae. 13837

\section{Publish your work in this journal}

Therapeutics and Clinical Risk Management is an international, peerreviewed journal of clinical therapeutics and risk management, focusing on concise rapid reporting of clinical studies in all therapeutic areas, outcomes, safety, and programs for the effective, safe, and sustained use of medicines. This journal is indexed on PubMed Central, CAS,
EMBase, Scopus and the Elsevier Bibliographic databases. The manuscript management system is completely online and includes a very quick and fair peer-review system, which is all easy to use. Visit http://www.dovepress.com/testimonials.php to read real quotes from published authors. 